\title{
Adjuvant radiotherapy versus observation following gross total resection for atypical meningioma: a systematic review and meta-analysis
}

Se-Woong Chun ${ }^{1 \dagger}$, Kyung Min Kim ${ }^{2 \dagger}$, Min-Sung Kim ${ }^{2 *}$, Ho Kang $^{2}$, Yun-Sik Dho ${ }^{3}$, Youngbeom Seo ${ }^{4}$, Jin Wook Kim², Yong Hwy Kim² and Chul-Kee Park ${ }^{2}$

\begin{abstract}
Background: The impact of adjuvant radiotherapy (RT) on atypical meningioma (AM) underwent a gross total resection (GTR) remains unclear, showing conflicting results from various studies. The objective of this study was to perform an updated meta-analysis for observational studies to determine the effect of adjuvant RT after GTR on local recurrence and survival outcomes compared to observation after GTR.

Methods: PubMed, Embase, and Web of Science were searched to identify comparative studies that reported outcomes of adjuvant RT versus observation for AM patients after GTR. Local recurrence rate, progression-free survival (PFS), overall survival (OS), and toxicities related to RT were considered as outcomes of interest. Differences between two cohorts were estimated by calculating odds ratios (OR) for $L R$ rate and hazard ratios (HR) for survival outcomes with 95\% confidence intervals (Cls) for meta-analysis, using R version 4.0 .3 software. Included studies were appraised with the Risk of Bias Assessment tool for Non-Randomized Studies. Outcome ratios were combined with the MantelHaenszel method and the inverse variance-weighted method, appropriately.

Results: Data from 30 studies involving 2904 patients (adjuvant RT: $n=737$; observation: $n=2167$ ) were eventually included. Significant reduction of local recurrence rate was seen in the adjuvant RT cohort compare to that in the observation cohort (OR 0.50; 95\% Cl 0.36-0.68; $p<0.0001$ ). Pooled HRs of PFS at 1-year, 3-year, 5-year, and > 5-year revealed that adjuvant RT was superior to observation. There was no significant difference in OS between the two cohorts during any period. Most toxicities were tolerable with grade 1 or 2 . There was no documented grade 5 toxicity.
\end{abstract}

Conclusions: For AM patients who underwent GTR, evidence suggested that adjuvant RT could potentially decrease local recurrence and improve PFS better than observation.

Keywords: Atypical meningioma, Gross total resection, Adjuvant, Radiotherapy, Postoperative

${ }^{*}$ Correspondence: ns.kimsk@gmail.com

tSe-Woong Chun and Kyung Min Kim contributed equally to this work as a first author

${ }^{2}$ Department of Neurosurgery, Seoul National University Hospital, Seoul

National University College of Medicine, 101 Daehak-ro, Jongno-gu, Seoul 03080, Korea

Full list of author information is available at the end of the article

\section{Introduction}

Since the implementation of the 2007 World Health Organization (WHO) grading classification, the first to consider brain invasion as a diagnostic criterion of atypical meningioma (AM), the proportion of $\mathrm{AM}$ in newly diagnosed meningioma has increased from less than $10 \%$ to approximately $20-35 \%$ [1-5]. Traditionally, 
maximal surgical resection has been considered as the most important factor for predicting the prognosis of AM. However, even a after gross total resection (GTR), recurrence can occur in a substantial portion of patients because of its unpredictable behavior and heterogeneity [6-8]. The recurrence of AM has been associated with significant morbidity and increased mortality. Thus, effort to reduce recurrence should be prioritized in the management of AM patients.

It is widely accepted that adjuvant radiotherapy (RT) can affect favorable prognosis of AM patients after a subtotal resection (STR). However, the impact of RT on AM patients after a GTR remains controversial. Several retrospective studies have investigated the effect of adjuvant RT compared to observation after GTR, showing inconsistent results most likely due to a small sample size of each study, especially in the cohort that receives adjuvant RT following GTR [6, 9-16]. Recently, two multicohorts non-randomized phase II observational studies have reported a potential benefit of local control with adjuvant RT after GTR in AM patients $[17,18]$. However, neither study was designed to directly compare adjuvant RT versus observation in AM patients with GTR. Two randomized phase III trial, ROAM/EORTC-1308 (Radiotherapy versus Observation following surgical resection of Atypical Meningioma/European Organization for Research and Treatment of Cancer-1308) and NRG-BN003 (Observation Versus Irradiation for a Gross Totally Resected Grade II Meningioma) are currently underway to investigate whether adjuvant RT is superior to observation for reducing the recurrence of AM after GTR $[19,20]$. Until results of these randomized trials are known, it is necessary to synthetically analyze outcomes of previously reported studies for deciding an optimal treatment strategy for AM patients after GTR.

The primary aim of the current study was to compare local recurrence and survival outcomes between adjuvant RT and observation cohorts of AM patients after GTR. To achieve this aim, we conducted an updated systematic review and meta-analysis for relevant clinical observational studies with a comparative design.

\section{Materials and methods}

\section{Search strategy and study selection criteria}

In accordance with the PRISMA (Preferred Reporting Items for Systematic Reviews and Meta-Analyses) statement [21], we performed a meta-analysis of clinical studies that investigated the effect of adjuvant RT after GTR on AM. A thorough search for eligible studies in electronic databases of PubMed, Embase, and Web of Science from inception to August 10th, 2020 was conducted by two independent researchers (M.S.K and S.W.C). Search strategies utilized for each database are presented in Additional file 1: Table S1. Search results were screened by scanning abstracts using the following exclusion criteria: case report, technical note, review, letter or conference abstract; duplicate study; single cohort study; article dedicated to adjuvant radiosurgery (e.g., gamma knife surgery, cyberknife, stereotactic linear accelerator-based radiosurgery), proton or carbon ion radiotherapy, or brachytherapy; and article not about the population of interest (e.g., clear cell meningioma, chordoid meningioma). After all retrieved studies were reviewed, reference lists of reviews were also screened for qualifying studies. Only articles in English were considered since Morrison et al. reported no significant difference in pooled effects from the use of language restrictions in systematic review-based meta-analysis in medicine [22]. No limitation was set on the date of publication. Any discrepancies between the two reviewers (M.S.K and S.W.C) were resolved by discussion.

\section{Inclusion criteria, data extraction, and quality assessment} The goal of the search was to find articles that met the following inclusion criteria: (1) articles that described two distinctive cohort groups of AM patients who received either GTR only (observation cohort) or adjuvant RT after GTR (adjuvant RT cohort); and (2) articles that reported the outcome of local recurrence rate, progression-free survival (PFS), and/or overall survival (OS) for each cohort. Studies with a non-homogeneous design that reported outcomes for AM with STR or malignant meningioma were included if they separately reported outcomes according to whether adjuvant RT was performed or not after GTR for AM. We excluded articles that included patients with extracranial AM, salvageable RT for recurrent AM after GTR, and neurofibromatosis.

The following data were extracted from selected studies: author of study, year of publication, study design, country that the study was conducted, period of research, version of adopted WHO classification, definition of GTR in each study, total number of each cohort, recurrence rate or number, PFS, OS, and any complication associated with adjuvant RT, if feasible. Toxicities of each study were reevaluated for grading using Common Terminology Criteria for Adverse Events (CTCAE) version 5.0.

The methodological quality for an individual article was assessed using the Risk of Bias Assessment tool for Non-Randomized Studies (RoBANS) [23]. Two authors (M.S.K and S.W.C) performed a quality appraisal of each study independently. A consensus was reached by discussion for any discrepancies among reviewers. 


\section{Statistical analyses}

The primary outcome was direct comparisons of local recurrence rate, PFS, and OS in the adjuvant RT and the observation cohort after GTR for AM. For analysis of local recurrence, numbers of recurred patients in the adjuvant RT and the observation cohort were identified. Odds ratios (OR) and 95\% confidence intervals (CIs) were combined using the Mantel-Haenszel statistical method. Hazard ratios (HR) and 95\% CIs were adopted as indicators of PFS and OS. HR and 95\% CIs were extracted directly from included articles. For articles containing only Kaplan-Meier curves, survival data was extracted indirectly using Engauge Digitizer version 12.1, and outcomes were then derived pursuant to methods proposed by Tierney et al. [24] Pooled HR was calculated using an inverse variance-weighted method. OR and $\mathrm{HR}<1$ denoted outcome that was greater in the adjuvant RT cohort. Fixed-effects or random-effects models were used depending on the study nature and statistical heterogeneity of included studies in each analysis.

Heterogeneity between studies were assessed using the Cochrane $\mathrm{Q}$ test and the Higgins $\mathrm{I}^{2}$ statics. If $p$ value of the Cochrane $\mathrm{Q}$ was less than 0.1 or $\mathrm{I}^{2}$ value was larger than $50 \%$, the presence of significant heterogeneity among studies was considered and a random-effects model was used. Otherwise, a fixed-effects model was employed. The risk of publication bias was evaluated statistically by calculation of the $p$ value (two-sided) for Egger's linear regression test and Begg rank correlation, and graphically by inspection of funnel plots. $p$ values of $>0.05$ in Egger's test and Begg rank correlation test were considered as absence of significant publication bias. All statistical analyses were performed using $\mathrm{R}$ version 4.0.3 (R Foundation for Statistical Computing, Vienna, Austria, 2008) and the meta package [25].

\section{Results}

\section{Literature search and study quality assessment}

The initial search identified 815 studies in PubMed, 1317 in Embase, and 506 in Web of Science (Fig. 1). A total of 1162 duplicate studies and 1386 studies were excluded according to inclusion and exclusion criteria after reviewing titles and abstracts. The remaining 90 studies were subsequently given a full-text review. Of them, 60 studies were excluded because available data were not extractable in studies with non-homogenous design $(n=26)$, lack of comparative study arm $(n=14)$, insufficient and indiscernible data $(n=17)$, patients with extracranial lesions $(\mathrm{n}=1)$, incomplete trial $(\mathrm{n}=1)$, and overlapping study population $(\mathrm{n}=1)$. Finally, a total of 30 studies were included in our meta-analysis (Table 1). Among these 30 studies included in the current meta-analysis, five had a homogenous study design, solely reporting the outcome of AM patients who underwent GTR. Twenty-five studies had a non-homogenous design, reporting about AM with STR $(n=22)$ or malignant meningioma $(n=3)$ as well as AM with GTR. All studies with a non-homogenous design contained extractable data for clearly defined outcomes, explicitly comparing observation and adjuvant RT after GTR for AM. All included studies had a retrospective design involving 2904 patients: 2167 were treated with GTR alone and 737 received adjuvant RT after GTR. GTR was defined as Simpson grade I-III in 19 studies, grade I-II in five studies, and grade I in three studies. Three studies described GTR or TR without using the Simpson grade.

Qualitative assessment of selected studies is summarized in Additional file 1: Table S2. The risk of bias in the selection of participants was high in two studies that included AM patients located only in the skull base [26] and lateral ventricle [27]. Twenty-five studies with a non-homogenous design had a high risk of confounding bias because confounding variables were not considered between the adjuvant RT or the observation cohort after GTR $[3,7,10,12,13,15,16,26-42]$. One study with a non-homogenous design that adjusted for major confounding variables using propensity score matching was considered to have a low risk of confounding bias [11]. One study with a homogenous study design had a high risk of confounding bias because of insufficient information for confounding variables [43]. The risk of performance bias due to an inadequate measurement of intervention was high in seven studies without a clear description of the definition of adjuvant RT $[7,11,12$, $14,15,29,44]$. The detection bias was low in all included studies. The attrition bias was high in 11 studies with missing data because of restriction in follow-up duration or loss to follow-up for analyzing the outcome $[3,10,30$, $35,36,39-43,45]$. The risk of reporting bias was high in five studies that did not report the recurrence number or the percentage of each cohort $[26,34,37,40,41]$.

\section{Local recurrence}

Of 30 studies included in our meta-analysis, 25 studies consisting of 1232 patients in the observation cohort and 384 in the adjuvant RT cohort reported relevant data regarding local recurrence after GTR for AM. The crude local recurrence rate in the adjuvant RT cohort was $18.23 \%(70 / 384)$, which was statistically lower than that $(24.68 \%, 304 / 1232)$ of the observation cohort $(p=0.009)$. Subsequent pooled analysis of these studies revealed that adjuvant RT reduced the risk of local recurrence (OR 0.50; 95\% CI $0.36-0.68 ; p<0.0001$ ) (Fig. 2a). Included studies had no significant heterogeneity $\left(\mathrm{I}^{2}=25 \%\right.$; $\left.\mathrm{Tau}^{2}=0.2446 ; p=0.13\right)$. Cumulative 


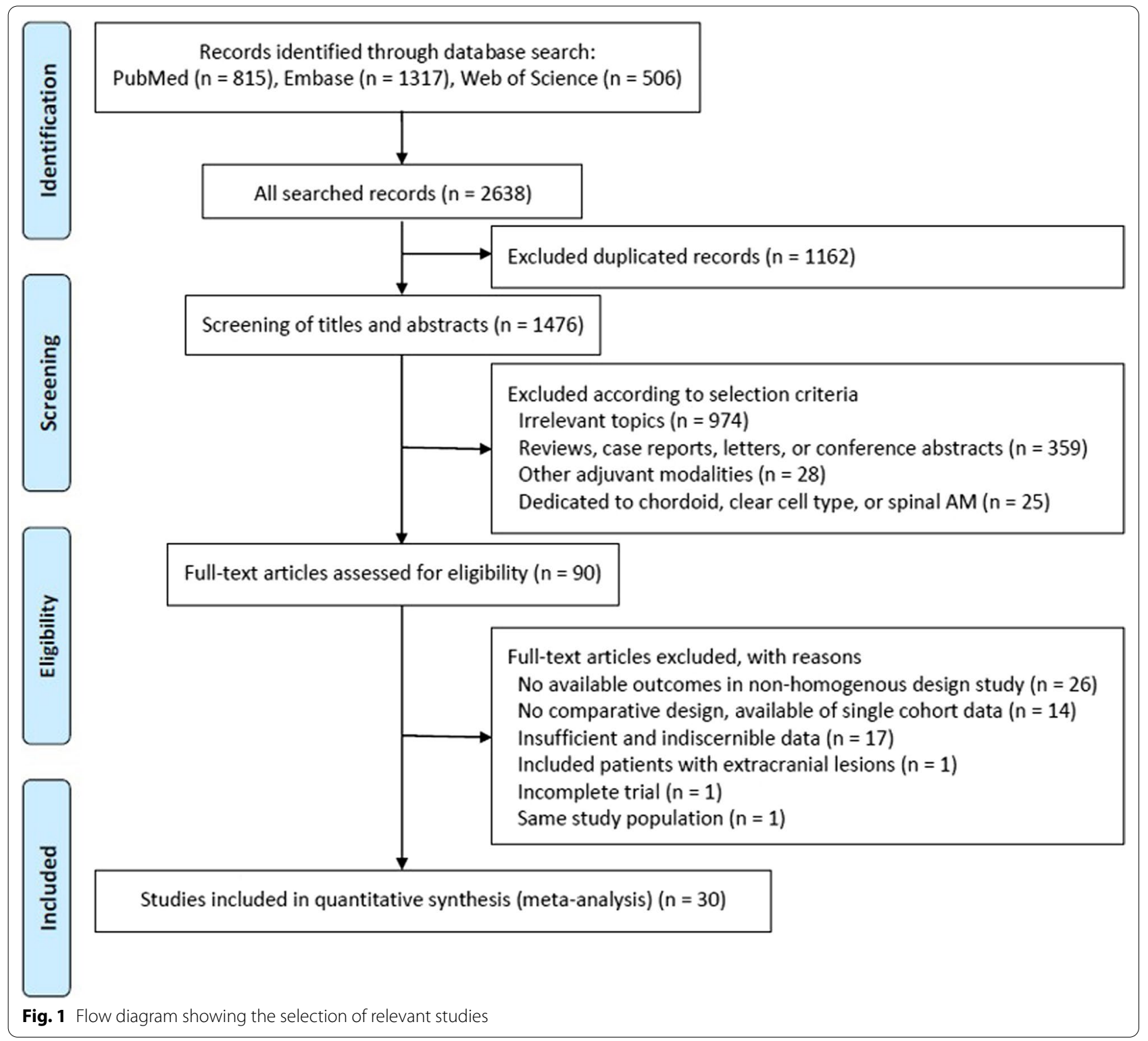

analysis according to the publication year of each study showed that the adjuvant RT cohort had a benefit in controlling local recurrence over the observation cohort, showing statistical significance in recent years (Fig. 2b).

A subgroup analysis based on the WHO classification applied in each study showed that the crude local recurrence rate in studies using the 2007 or 2016 WHO classification was $17.65 \%(30 / 170)$ in the adjuvant RT cohort, which was significantly better than that $(31.14 \%, 147 / 472)$ in the observation cohort $(p=0.001)$. Pooled analysis of studies of this subgroup showed significant advantage of adjuvant RT compared to observation in terms of local recurrence of AM patients after GTR (OR 0.45; 95\% CI 0.29-0.72; $p=0.0007$ ) (Fig. 3b). Included studies had no significant heterogeneity $\left(\mathrm{I}^{2}=0 \%\right.$; $\left.\mathrm{Tau}^{2}=0 ; p=0.50\right)$. In subgroup analysis of studies using the 1993 or 2000 WHO classification, there was no significant difference in crude local recurrence rate between the observation cohort (16.67\%) and the adjuvant RT cohort $(16.28 \% ; p=0.951)$. Pooled analysis of corresponding studies showed no significant difference in local recurrence between the adjuvant RT cohort and the observation cohort (OR 0.79; 95\% CI $0.14-4.51 ; p=0.7910$ ) (Fig. 3a). A random-effect model was applied because of significant heterogeneity $\left(\mathrm{I}^{2}=67 \%\right.$; $\left.\mathrm{Tau}^{2}=2.0826 ; p=0.03\right)$ among studies in this subgroup. 
Table 1 Baseline characteristics of included studies

\begin{tabular}{|c|c|c|c|c|c|c|c|}
\hline \multirow[t]{2}{*}{ References } & \multirow[t]{2}{*}{ Country } & \multirow[t]{2}{*}{ Design } & \multirow[t]{2}{*}{ Study period } & \multirow[t]{2}{*}{ WHO criteria } & \multirow[t]{2}{*}{ Simpson grade } & \multicolumn{2}{|c|}{ No. of patients } \\
\hline & & & & & & Adjuvant RT & Observation \\
\hline Condra et al. [28] & USA & R, OS, 1 institution & 1964-1992 & 1993 & $1,2,3$ & 4 & 21 \\
\hline Aghi et al. [44] & USA & R, OS, 1 institution & 1993-2004 & NR & 1 & 8 & 100 \\
\hline Jo et al. [29] & Korea & R, OS, 1 institution & 1997-2008 & 2000 & 1 & 19 & 13 \\
\hline Yu et al. [43] & China & R, OS, 1 institution & $2003-2008$ & NR & $1,2,3$ & 47 & 11 \\
\hline Komotar et al. [9] & USA & R, OS, 1 institution & 1992-2011 & 1993 & 1,2 & 13 & 32 \\
\hline Lee et al. [30] & USA & R, OS, 1 institution & 1999-2009 & 2007 & $1,2,3$ & 17 & 54 \\
\hline Park et al. [10] & Korea & R, OS, 1 institution & $1997-2011$ & 2000/2007 & $1,2,3$ & 17 & 38 \\
\hline Aizer et al. [11] & USA & R, OS, 1 institution & 1997-2011 & NR & $1,2,3$ & 18 & 50 \\
\hline Sun et al. [45] & USA & R, OS, 1 institution & 1993-2012 & 2007 & $1,2,3$ & 39 & 112 \\
\hline Yoon et al. [12] & USA & $\mathrm{R}, \mathrm{OS}, 2$ institutions & 2000-2010 & 2000 & $1,2,3$ & 7 & 102 \\
\hline Wang et al. [26] & Taiwan & R, OS, 1 institution & $2001-2009$ & 2007 & GTR & 3 & 11 \\
\hline Jenkinson et al. [7] & UK & R, OS, 3 institutions & $2001-2010$ & $2000 / 2007$ & $1,2,3$ & 32 & 81 \\
\hline Yip et al. [32] & Taiwan & R, OS, 1 institution & $2005-2014$ & NR & $\mathrm{TR}$ & 7 & 16 \\
\hline Endo et al. [31] & Japan & R, OS, 1 institution & 2000-2013 & 2007 & 1,2 & 11 & 19 \\
\hline Bagshaw et al. [13] & USA & R, OS, 1 institution & $1991-2014$ & 2007 & $1,2,3$ & 12 & 40 \\
\hline Graffeo et al. [14] & USA & R, OS, 1 institution & 1988-2011 & 2016 & $1,2,3$ & 8 & 61 \\
\hline Dohm et al. [34] & USA & R, OS, 1 institution & 1993-2014 & 2007 & $1,2,3$ & 12 & 37 \\
\hline Alghamdi et al. [3] & Canada & R, OS, 1 institution & 2003-2013 & NR & GTR & 1 & 43 \\
\hline Cho et al. [33] & Korea & R, OS, 1 institution & 2003-2014 & $2000 / 2007$ & 1,2 & 13 & 16 \\
\hline Shakir et al. [36] & Canada & R, OS, 1 institution & 1992-2013 & 2007 & $1,2,3$ & 12 & 28 \\
\hline Chen et al. [15] & USA & R, OS, 1 institution & 1993-2014 & 1993/2000/2007 & $1,2,3$ & 10 & 104 \\
\hline Budohoski et al. [35] & UK & R, OS, 3 institutions & $2007-2014$ & 2016 & $1,2,3$ & 35 & 108 \\
\hline Zeng et al. [40] & China & R, OS, SEER data & 2008-2015 & 2007 & $1,2,3$ & 194 & 533 \\
\hline Zhi et al. [41] & USA & R, OS, 1 institution & 2000-2012 & $2000 / 2007$ & $1,2,3$ & 26 & 72 \\
\hline Wang et al. [39] & USA & R, OS, 1 institution & $2009-2018$ & 2016 & $1,2,3$ & 71 & 142 \\
\hline Lee et al. [16] & Korea & R, OS, 1 institution & $2000-2013$ & 2007 & $1,2,3$ & 20 & 24 \\
\hline Ros-Sanjuan et al. [38] & Spain & R, OS, 1 institution & 1994-2014 & 2016 & 1 & 5 & 5 \\
\hline Li et al. [37] & China & R, OS, 1 institution & 2008-2015 & NR & 1,2 & 50 & 151 \\
\hline Lee et al. [42] & USA & R, OS, 1 institution & 2000-2015 & $2000 / 2007$ & $1,2,3$ & 18 & 133 \\
\hline Jiang 2020 [27] & China & R, OS, 1 institution & 2008-2016 & 2007 & 1,2 & 8 & 10 \\
\hline
\end{tabular}

R, retrospective; OS, observational study; WHO, World Health Organization; GTR, gross total resection; RT, radiotherapy; SEER, Surveillance, Epidemiology, and End Results; NR, not reported

\section{Survival outcomes}

PFS and OS were evaluated at each period of 1-year, 3 -year, 5-year, and > 5-year. Serially pooled HRs of PFS revealed that adjuvant RT was superior to observation after GTR for AM, showing sustained significance with a long-term follow-up (Fig. 4). Actuarial 1, 3, and 5 -year PFS rates were $93.4 \%, 84.7 \%$, and $80.5 \%$, respectively, in the adjuvant RT cohort. These rates were $88.8 \%, 77.8 \%$, and $68.3 \%$, respectively, in the observation cohort. However, pooled HR of OS showed no significant differences between the adjuvant RT cohort and the observation cohort after GTR for AM (Fig. 5). Actuarial 1, 3, and 5-year OSs rate were 96.8\%, 90.6\%, and $86.1 \%$, respectively, in the adjuvant RT cohort. These rates were $96.1 \%, 91.6 \%$, and $86.6 \%$, respectively, in the observation cohort.

\section{Toxicities of Radiation}

Adverse events related to RT were reported in 13 studies. Information on radiotherapy and adverse events of each study based on CTCAE 5.0 are presented in Table 2. There was no documented event of Grade 5 toxicity. Most toxicities were consistent with Grade 1 or 2 . Grade 3 and 4 toxicities were reported in 7 (2.1\%) and 9 patients $(2.7 \%)$, respectively. 


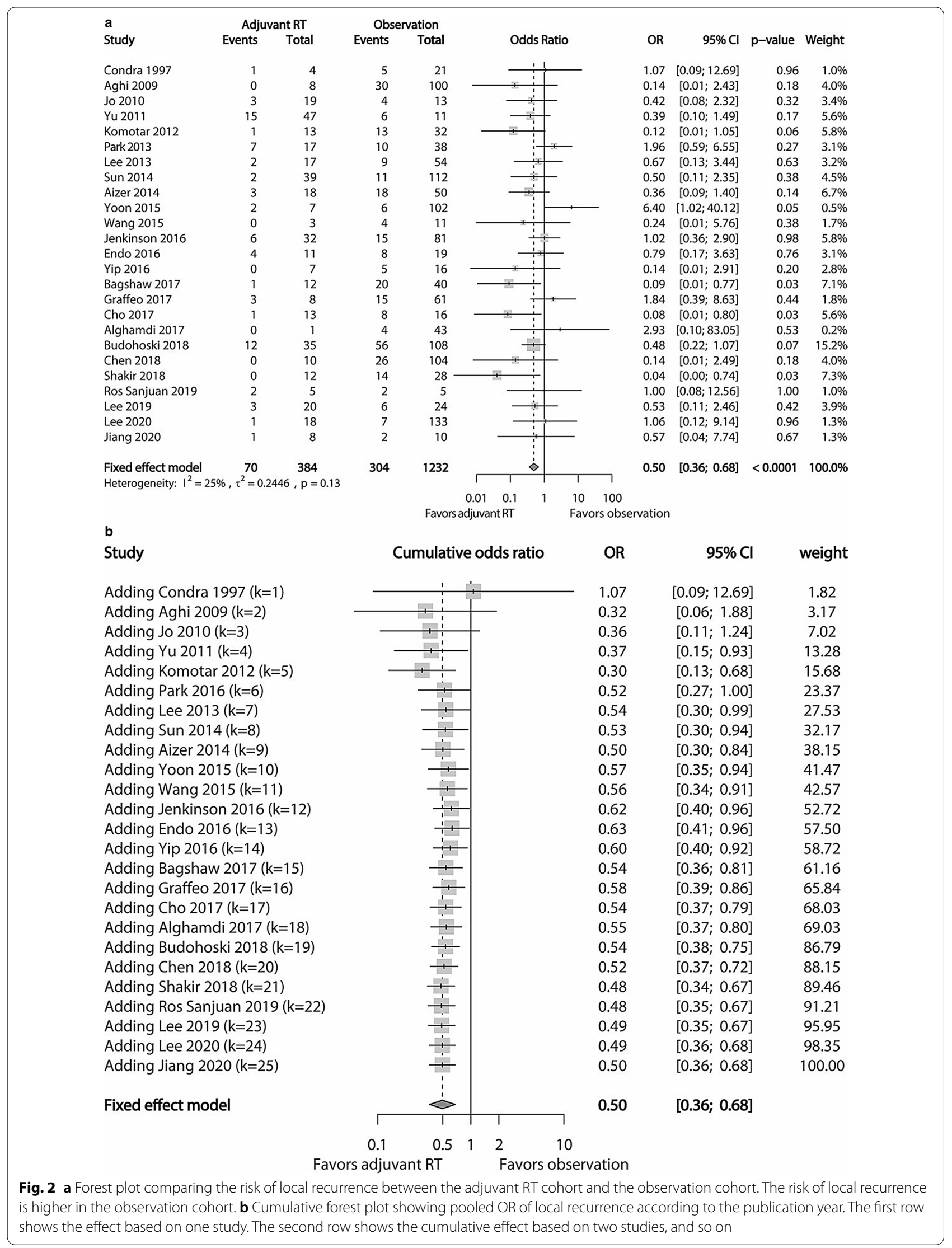




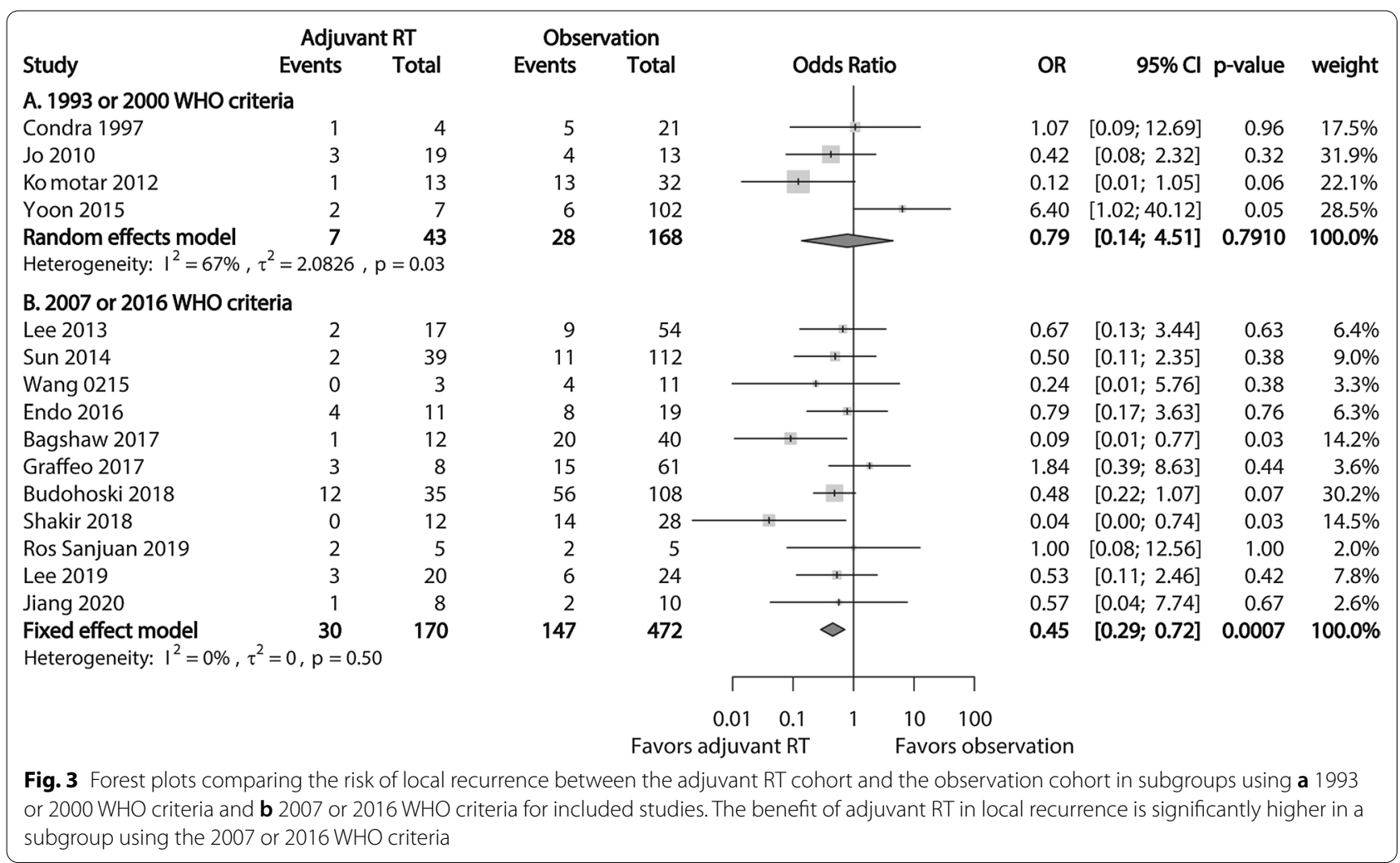

\section{Publication bias}

Publication bias results of included studies are shown in Table 3. All results of Egger's test and Begg rank correlation had $p$ value $>0.5$ with relatively symmetric funnel plots, indicating no substantial evidence for publication bias in the dataset.

\section{Discussion}

The current meta-analysis included 30 studies with 2167 patients in the observation cohort and 737 patients in the adjuvant RT cohort. The local recurrence rate was lower in the adjuvant RT cohort than that in the observation cohort. However, in subgroup analysis, this result was proven to be true for studies using the 2007 or 2016 WHO classification, but not for those adopting previous classifications. PFS was better in the adjuvant RT cohort than in the observation cohort regardless of the followup term. However, OS did not differ significantly between the two cohorts.

The impact of adjuvant RT following GTR on AM patients compared to observation remains controversial. Management strategies among physicians also vary in clinical practice due to conflicting results of previous individual studies [46]. A past meta-analysis has reported that postoperative RT may decrease the risk of tumor recurrence for AM patients after GTR [47]. However, it is controversial to determine the effectiveness of adjuvant RT compared to observation based on this single metaanalysis. It included only 14 studies published by 2012 with a relatively small number of total subjects $(n=757)$. Additionally, it included several studies with single-arm design which had an innate bias in assessing outcomes of relative values. Many studies have been reported since then. Outcomes of these studies should be considered for analyzing the benefit of adjuvant RT over observation following GTR for AM patients. We conducted an upto-date and systematic review and meta-analysis involving 2167 patients in the observation cohort and 737 in the adjuvant RT cohort. In the present meta-analysis, we found that adjuvant RT had a benefit of decreasing local recurrence rate (OR $0.50 ; p<0.0001$ ) compared to observation for AM patients after GTR. Furthermore, the pooled outcome of prolonged PFS (HR: 0.67; $p=0.0024$ ) also showed a high statistical significance that individual studies failed to confirm due to their small sample sizes. Results of the current study can help us establish appropriate management strategy for AM patients following GTR in clinical practice.

In general, brain invasion had long been recognized as an adverse factor that is related to a higher risk of local recurrence $[44,45,48-50]$. To reflect this widespread conception, the $2007 \mathrm{WHO}$ classification first considered 


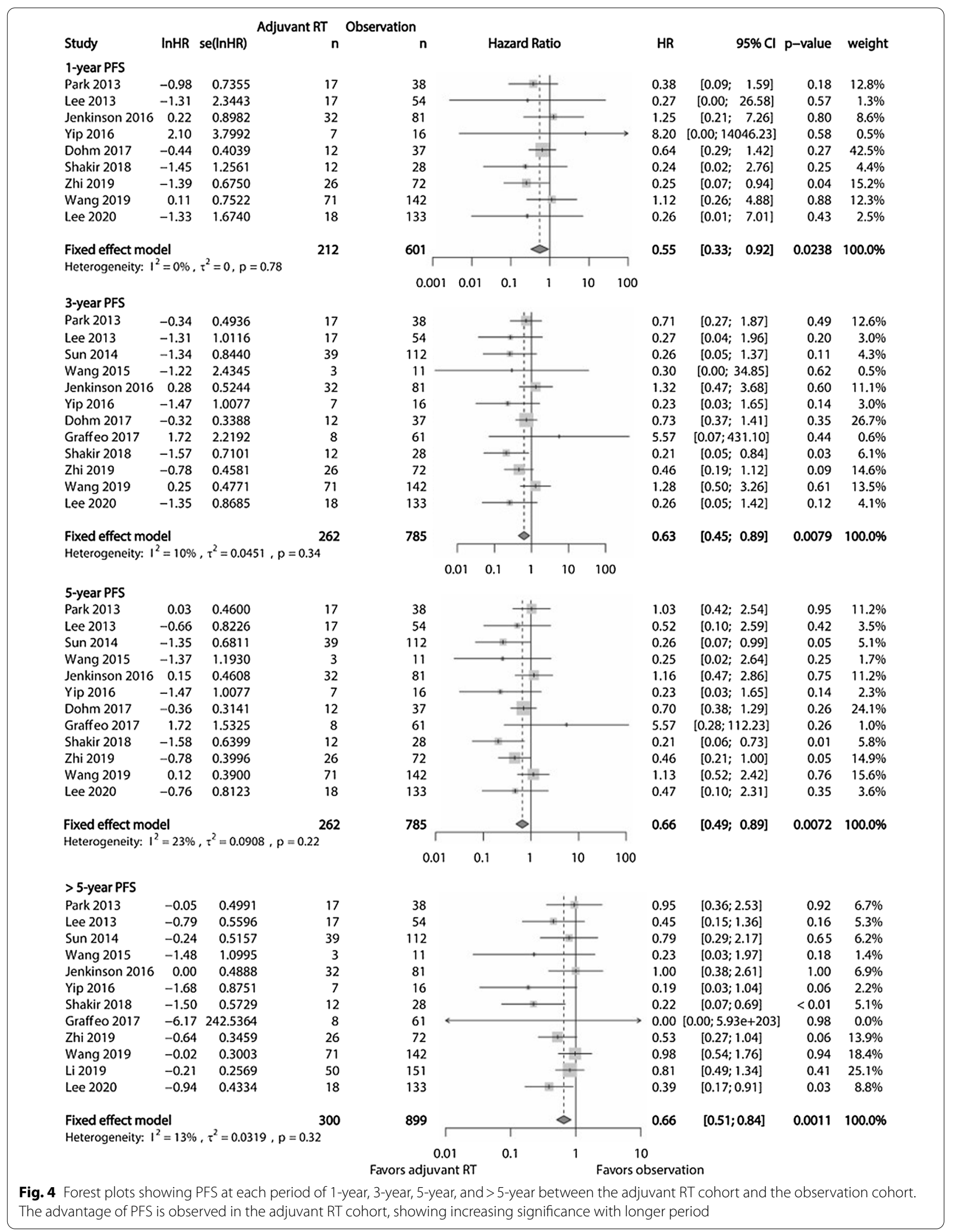




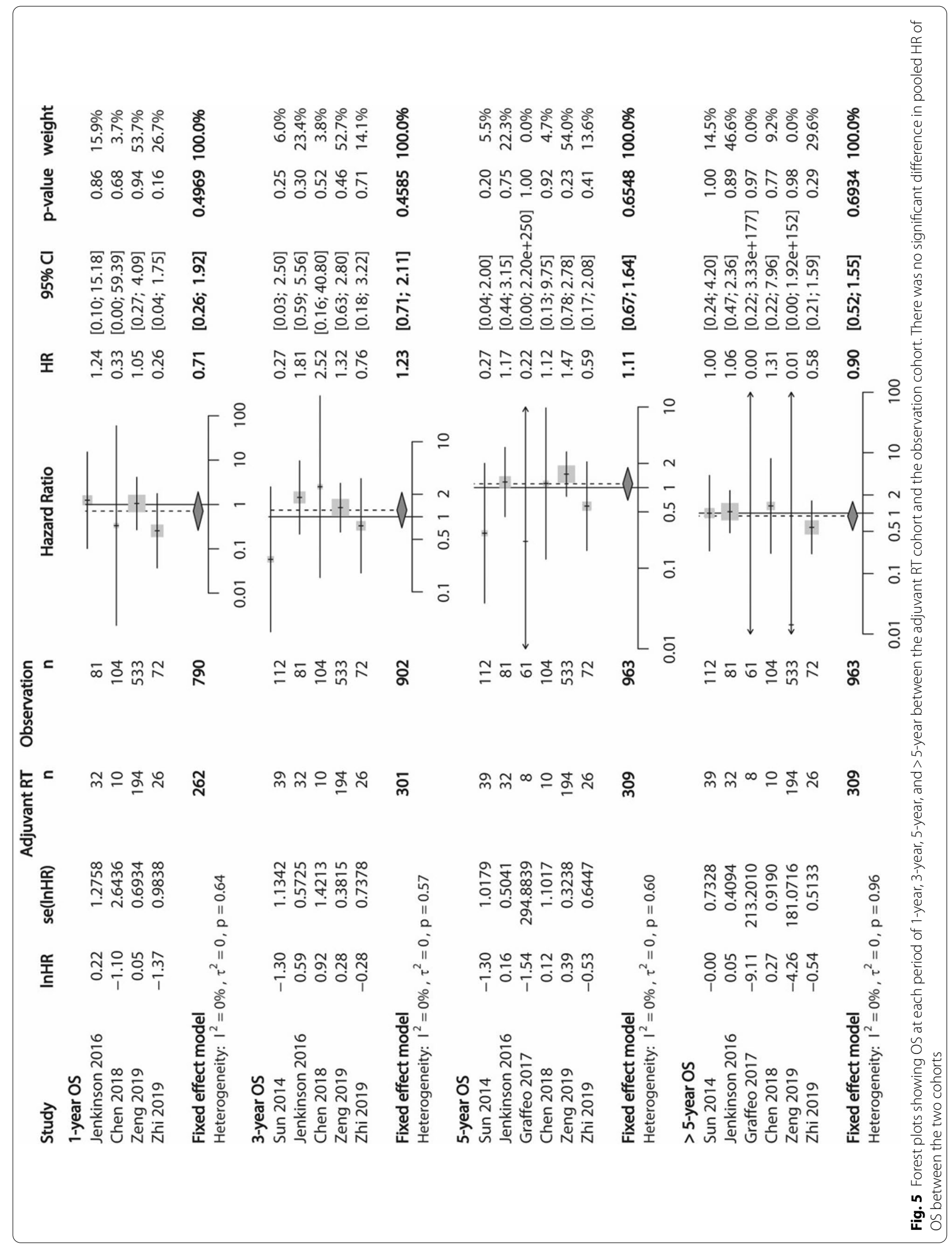


Table 2 Toxicities of radiotherapy

\begin{tabular}{|c|c|c|c|c|c|c|}
\hline \multirow[t]{2}{*}{ Study } & \multirow[t]{2}{*}{ No. of patients } & \multirow[t]{2}{*}{ Radiation technology } & \multicolumn{3}{|c|}{ Radiation dose (Gy) } & \multirow{2}{*}{$\begin{array}{l}\text { Adverse events according } \\
\text { to CTCAE grade (No. } \\
\text { of patients) }\end{array}$} \\
\hline & & & Median & Range & Per fx (no. of fx) & \\
\hline Aghi et al. [44] & 8 & NR & $60.2^{+}$ & $59.4-61.2$ & $1.5-1.8$ & $\begin{array}{l}\text { Grade } 4 \text { radiation necrosis } \\
(n=1)\end{array}$ \\
\hline Komotar et al. [9] & 13 & NR & 59.4 & NR & $1.8-2.0$ & $\begin{array}{l}\text { Grade } 1-2 \text { skin dermatitis, } \\
\text { erythema, alopecia, fatigue, } \\
\text { and headache (NR) }\end{array}$ \\
\hline Park et al. [10] & $17+10^{*}$ & Conventional RT/ 3D-CRT & 61.2 & $40.0-61.2$ & NR (30-35) & $\begin{array}{l}\text { Grade } 1-2 \text { fatigue, headache, } \\
\text { nausea, dizziness, skin irrita- } \\
\text { tion (NR) }\end{array}$ \\
\hline Aizer et al. [11] & $18+12^{*}$ & NR & 60.0 & $55.8-64.0$ & NR & $\begin{array}{l}\text { Grade } 4 \text { radiation related } \\
\text { glioblastoma }(n=1)\end{array}$ \\
\hline Sun et al. [45] & 39 & NR & 53.8 & $46.0-60.0$ & $1.7-2.0$ & $\begin{array}{l}\text { Grade } 1-2 \text { radiation necrosis } \\
\quad(n=1) \\
\text { Grade } 4 \text { radiation necrosis } \\
(n=3)\end{array}$ \\
\hline Wang et al. [26] & $3+9^{*}$ & NR & NR & $54.0-60.0$ & NR (27-30) & $\begin{array}{l}\text { Grade } 1-2 \text { headache, dizzi- } \\
\text { ness, and skin irritation (NR) }\end{array}$ \\
\hline Bagshaw et al. [13] & $12+9^{*}$ & NR & 54.0 & $45.0-59.4$ & NR & $\begin{array}{l}\text { Grade } 1 \text { fatigue, headache, } \\
\text { and seizure }(n=4) \\
\text { Grade } 2 \text { headache, dizziness, } \\
\text { alopecia, and hearing and } \\
\text { memory impairment }(n=4) \\
\text { Grade } 3 \text { radiation necrosis } \\
(n=2) \\
\text { Grade } 4 \text { optic nerve disorder } \\
(n=1)\end{array}$ \\
\hline Graffeo et al. [14] & 8 & NR & 54.0 & $50.5-61.2$ & NR (28-30) & $\begin{array}{l}\text { Undetermined grade major } \\
\text { morbidity }(n=1)\end{array}$ \\
\hline Dohm et al. [34] & $12+51^{*}$ & 3D-CRT & 55.7 & $50.4-59.4$ & NR (28-35) & $\begin{array}{l}\text { Grade } 4 \text { seizure }(n=1) \\
\text { Grade } 3 \text { radiation necrosis, } \\
\text { cognitive disturbance, } \\
\text { peripheral neuropathy, } \\
\text { seizure, aphasia, and optic } \\
\text { nerve disorders }(n=7)\end{array}$ \\
\hline Cho et al. [33] & $13+21^{*}$ & Conventional RT & $N R$ & $30.0-61.2$ & NR (30-35) & $\begin{array}{l}\text { Grade 1-2 fatigue, headache, } \\
\text { nausea, dizziness, and skin } \\
\text { irritation (NR) }\end{array}$ \\
\hline Shakir et al. [36] & $12+3^{*}$ & 3D-CRT & 54.0 & $52.2-59.4$ & 1.8 & $\begin{array}{l}\text { Grade } 1-2 \text { headache, diz- } \\
\text { ziness, and paresthesia } \\
(n=8)\end{array}$ \\
\hline Lee et al. [16] & $20+33^{*}$ & 3D-CRT/IMRT & $50.4 / 54.0$ & $36.0-64.0 / 50.4-59.4$ & $1.8-2.0$ & $\begin{array}{l}\text { Grade } 1 \text { radiation necrosis } \\
\quad(n=2)\end{array}$ \\
\hline Ros-Sanjuan et al. [38] & $5+8^{*}$ & 3D-CRT & NR & NR & NR & $\begin{array}{l}\text { Undetermined grade radia- } \\
\text { tion necrosis }(n=1)\end{array}$ \\
\hline
\end{tabular}

CTCAE, Common Terminology Criteria for Adverse Events; RT, radiotherapy; 3D-CRT, three-dimensional conformal radiotherapy; IMRT, intensity-modulated radiotherapy; NR, not reported

*Patients no. such as AM with STR or malignant meningioma who underwent RT in studies with non-homogenous design

${ }^{\dagger}$ Indicate mean value

brain invasion as a staging feature in the diagnosis of AM. In the 2016 WHO classification, brain invasion was eventually included as a criterion that was sufficient for diagnosing AM by itself [2]. In our subgroup analysis of studies using the 2007 or 2016 WHO classification, adjuvant RT significantly reduced local recurrence (OR 0.45 ; $p=0.0007)$ with a low recurrence rate $(17.65 \%)$ compare to observation (31.14\%) for AM patients after GTR. This result implies the utility of adjuvant RT for AM patients after GTR, especially in the current era of the 2016 WHO classification when the diagnosis of AM is increasing. Unlike the subgroup analysis of studies using the 2007 or 2016 WHO classification, the subgroup analysis of studies on patients with AM according to the 1993 or 2000 WHO classification which did not include brain invasion as a diagnostic feature showed no significant difference 
Table 3 Summary of the publication bias in each meta-analysis

\begin{tabular}{|c|c|c|c|c|c|c|c|c|c|}
\hline \multicolumn{2}{|c|}{ Evaluation index } & \multicolumn{5}{|c|}{ Egger's linear regression test } & \multicolumn{3}{|c|}{ Begg rank correlation } \\
\hline & & Intercept & SE & $95 \% \mathrm{Cls}$ & $\mathrm{t}$ value & $p$ value & Tau & $z$ value & $p$ value \\
\hline \multirow[t]{3}{*}{ LR } & Overall & -0.839 & 0.590 & -2.060 to 0.382 & 1.422 & 0.169 & -0.197 & 1.378 & 0.168 \\
\hline & 1993/2000 WHO criteria & -1.911 & 7.191 & -32.852 to 29.031 & 0.266 & 0.815 & 0 & 0 & 1.000 \\
\hline & 2007/2016 WHO criteria & -0.626 & 0.727 & -2.271 to 1.018 & 0.862 & 0.411 & -0.255 & 1.090 & 0.276 \\
\hline \multirow[t]{4}{*}{ PFS } & 1-year & -0.080 & 0.546 & -1.371 to 1.211 & 0.147 & 0.888 & 0.139 & 0.521 & 0.602 \\
\hline & 3-year & -0.794 & 0.675 & -2.298 to 0.710 & 1.177 & 0.267 & -0.076 & 0.343 & 0.732 \\
\hline & 5-year & -0.791 & 0.815 & -2.607 to 1.024 & 0.971 & 0.354 & -0.106 & 0.480 & 0.631 \\
\hline & >5-year & -1.094 & 0.662 & -2.570 to 0.382 & 1.652 & 0.130 & -0.409 & 1.851 & 0.064 \\
\hline \multirow[t]{4}{*}{ OS } & 1-year & -0.519 & 1.114 & -5.314 to 4.276 & 0.466 & 0.687 & -0.167 & 0.340 & 0.734 \\
\hline & 3-year & -0.668 & 0.969 & -3.752 to 2.416 & 0.689 & 0.540 & -0.100 & 0.245 & 0.807 \\
\hline & 5-year & -0.737 & 0.588 & -2.371 to 0.896 & 1.253 & 0.279 & -0.400 & 1.127 & 0.260 \\
\hline & >5-year & 0.026 & 0.338 & -0.913 to 0.965 & 0.077 & 0.942 & -0.267 & 0.751 & 0.452 \\
\hline
\end{tabular}

LR, local recurrence; PFS, progression-free survival; OS, overall survival; WHO, World Health Organization; SE, standard error; Cls, confidence intervals

in local recurrence rate between adjuvant RT and observation cohorts. Results of current meta-analyses are emphatic about the need of integrative assessment of brain invasion for higher accuracy using multimodalities such as histopathological, operative, and image findings for establishing appropriate treatment for AM patients.

In the current meta-analysis, there was no statistical difference in pooled OS for any period between adjuvant RT and observation cohorts, in line with results of included individual studies [39, 40]. Zeng et al. have reported that the OS of AM patients who undergo GTR only is similar to that of patients who receive adjuvant RT after GTR or STR regardless of the extent of resection [40]. The extent of resection for AM can be an overwhelmingly significant factor to improve the OS, enough to conceal the effect of adjuvant RT. The improvement of salvageable modalities for recurrent AM might have mitigated the difference of OS between two cohorts. Several studies have reported the benefit of survival extension through salvage therapy using ion radiotherapy, brachytherapy, and radiosurgery [51-53]. Despite the benefit of salvage therapy, aggressive upfront treatment after the first surgery for AM should be considered because of a low durability in local control of salvage therapy [51]. Furthermore, recurrent meningioma tends to be more aggressive than the original tumor, causing failure of salvage therapy. It may offset the effect of adjuvant RT on OS of AM patients [28, 54, 55].

Neurotoxicity of adjuvant RT is a major cause that makes physicians hesitate to apply it for AM patients after GTR. The incidence of neurotoxicity varies, ranging from $3.4 \%$ to $16.7 \%$ according to the location of the lesion, radiation dose, and radiation modality. However, advanced techniques for RT can lead to improvement in side effect profile and conventional fractionation RT can provide a far lower toxicity than hypofractionation RT or radiosurgery [56, 57]. Furthermore, most neurotoxicities are within tolerable levels using proper medical treatment [58]. In a phase II parallel observation study (EORTC 22,042-26,042), Weber et al. have reported that the rate of late adverse effect of CTCAE grade 3 or more associated with adjuvant RT following GTR for AM is $14.3 \%(3 / 56)$ and that there is no toxic death (grade 5) [18]. In studies included in the current review, no death related to $\mathrm{RT}$ was reported and the occurrence of toxicities of grade 3 or more was $5.4 \%$ (18/336). Documented grade 4 toxicities included radiation necrosis $(n=4)$, optic nerve disorder $(n=1)$, seizure $(n=1)$, and radiation-related glioblastoma $(n=1)$. Although toxicities are usually mild, serious toxicity such as optic neuropathy and radiation-induced malignancy should not be overlooked when considering adjuvant RT for AM patients after GTR. Therefore, it is imperative to carefully adjust the radiation dose and elaborate radiation technique to maximize the efficacy and minimize the toxicity in accordance with each patient. Additionally, although the toxicity of adjuvant RT is at low-level, risk factors for recurrence in AM patients after GTR should be considered to avoid unnecessary toxicity and select proper candidates of adjuvant RT. Chen et al. have reported that AM with MIB labelling index $\leq 7 \%$ have a very low risk (RR 0.06 ; 95\% CI 0.003-0.32; $p=0.0004$ ) of recurrence after GTR [15]. Tumor size, secondary AM, and bone involvement have been reported in prior studies as risk factors of recurrence for AM patients after GTR [15, 39].

Several limitations exist in the present meta-analysis. First and foremost, it should be noted that all studies included were retrospective in nature, thus limiting implications of results. Another up-to-date 
meta-analysis with the strongest level of evidence using two randomized phase II trials (ROAM/EORTC-1308 and NRG-BN003) will be performed in the future after these trials are completed. Second, like all meta-analyses, pooled results need to be interpreted acknowledging that local recurrence and survival outcomes can vary according to individual patients. Third, because of an insufficient number of studies with a homogenous design solely reporting outcomes of AM with GTR, we included studies with a non-homogenous design which might have caused confounding bias due to the fact that individual studies did not report confounding variables such as age, sex, location of the mass, or follow-up period according to the two cohorts of our interest. To reduce this risk of bias and provide an objective evaluation, we conducted meta-analyses using only dataset of direct comparative studies. Moreover, heterogeneities of most pooled analyses were low and acceptable except in analysis about local recurrence of studies using the 1993 or 2000 WHO criteria showing significant heterogeneity. Thus, the current meta-analyses about local recurrence and survival outcome have significant implications about the effect of adjuvant RT after GTR on AM patients compared to observation after GTR. Finally, the systematic review of toxicity should be interpreted with caution because it included adverse effects occurring in patient populations not strictly confined to those with AM and received adjuvant RT after GTR.

\section{Conclusions}

Currently, available evidence supports the finding that adjuvant RT confers significant benefits for local control and PFS compared to observation in AM patients after GTR. However, adjuvant RT should be carefully considered to avoid unforeseen complications related to RT. It should be performed for AM patients with a high risk of recurrence after GTR. Randomized controlled trials are necessary to provide further evidence for our results and assess which AM patients could have the greatest clinical benefit and the lowest toxicity of adjuvant RT following GTR.

\section{Supplementary Information}

The online version contains supplementary material available at https://doi. org/10.1186/s13014-021-01759-9.

Additional file 1: Supplementary tables for search strategies, quality assessment of the studies by RoBANS, and PRISMA 2009 Checklists.

Acknowledgements

There are no acknowledgements to report.

\section{Authors' contributions}

Conception and design: M.S.K. Acquisition of data: M.S.K and S.W.C. Analysis and interpretation of data: M.S.K and S.W.C. Drafting the article: M.S.K and K.M.K. Critically revising the article: S.W.C and K.M.K. Reviewed submitted version of manuscript: all authors.. Approved the final version of the manuscript: all authors.. Statistical analysis: M.S.K and S.W.C. Administrative/technical/material support: K.M.K, H.K, Y.S.D, Y.S, and J.W.K. Study supervision: M.S.K, Y.H.K, and C.K.P. All authors read and approved the final manuscript.

\section{Funding}

This study received no financial or material support that might cause a conflict of interest.

\section{Availability of data and materials}

All data generated or analyzed during this study are included in this manuscript.

Ethics approval and consent to participate

Not applicable.

\section{Consent for publication \\ Not applicable.}

\section{Competing interests}

The authors have no conflicts of interest relevant to this study to disclose.

\section{Author details}

${ }^{1}$ Department of Rehabilitation Medicine, Gyeongsang National University Changwon Hospital, Gyeongsang National University School of Medicine, Changwon, Korea. ${ }^{2}$ Department of Neurosurgery, Seoul National University Hospital, Seoul National University College of Medicine, 101 Daehak-ro, Jongno-gu, Seoul 03080, Korea. ${ }^{3}$ Department of Neurosurgery, Chungbuk National University Hospital, Chungbuk National University College of Medicine, Cheongju, Korea. ${ }^{4}$ Department of Neurosurgery, Yeungnam University Hospital, Yeungnam University College of Medicine, Daegu, Korea.

Received: 25 November 2020 Accepted: 28 January 2021

Published online: 17 February 2021

\section{References}

1. Rogers L, Barani I, Chamberlain M, Kaley TJ, McDermott M, Raizer J, et al. Meningiomas: knowledge base, treatment outcomes, and uncertainties. A RANO review. J Neurosurg. 2015;122(1):4-23.

2. Louis DN, Perry A, Reifenberger G, von Deimling A, Figarella-Branger D, Cavenee WK, et al. The 2016 World Health Organization classification of tumors of the central nervous system: a summary. Acta Neuropathol. 2016;131(6):803-20

3. Alghamdi M, Li H, Olivotto I, Easaw J, Kelly J, Nordal R, et al. Atypical meningioma: referral patterns, treatment and adherence to guidelines. Can J Neurol Sci. 2017:44(3):283-7.

4. Coppola F, Campbell JI, Herrero JM, Volpe E, Cersosimo T. Comparative analysis of Grade I vs Grade II intracranial meningiomas in a retrospective series of 63 patients. Surg Neurol Int. 2017;8(Suppl 2):S37-42.

5. Bulleid LS, James Z, Lammie A, Hayhurst C, Leach PA. The effect of the revised WHO classification on the incidence of grade II meningioma. $\mathrm{Br} J$ Neurosurg. 2019;9:1-3.

6. Stark AM, Buhl R, Mehdorn HM. Early gross recurrence of atypical meningioma. J Neurooncol. 2005;75(2):223-4.

7. Jenkinson MD, Wagar M, Farah JO, Farrell M, Barbagallo GM, McManus R, et al. Early adjuvant radiotherapy in the treatment of atypical meningioma. J Clin Neurosci. 2016;28:87-92.

8. Pereira BJA, de Almeida AN, Paiva WS, Teixeira MJ, Marie SKN. Impact of radiotherapy in atypical meningioma recurrence: literature review. Neurosurg Rev. 2019;42(3):631-7.

9. Komotar RJ, lorgulescu JB, Raper DM, Holland EC, Beal K, Bilsky MH, et al. The role of radiotherapy following gross-total resection of atypical meningiomas. J Neurosurg. 2012;117(4):679-86. 
10. Park HJ, Kang HC, Kim IH, Park SH, Kim DG, Park CK, et al. The role of adjuvant radiotherapy in atypical meningioma. J Neurooncol. 2013;115(2):241-7.

11. Aizer AA, Arvold ND, Catalano P, Claus EB, Golby AJ, Johnson MD, et al. Adjuvant radiation therapy, local recurrence, and the need for salvage therapy in atypical meningioma. Neuro Oncol. 2014;16(11):1547-53.

12. Yoon H, Mehta MP, Perumal K, Helenowski IB, Chappell RJ, Akture E, et al. Atypical meningioma: randomized trials are required to resolve contradictory retrospective results regarding the role of adjuvant radiotherapy. $J$ Cancer Res Ther. 2015;11(1):59-66.

13. Bagshaw HP, Burt LM, Jensen RL, Suneja G, Palmer CA, Couldwell WT, et al. Adjuvant radiotherapy for atypical meningiomas. J Neurosurg. 2017:126(6):1822-8.

14. Graffeo CS, Leeper HE, Perry A, Uhm JH, Lachance DJ, Brown PD, et al. Revisiting adjuvant radiotherapy after gross total resection of World Health Organization Grade II meningioma. World Neurosurg. 2017; 103:655-63.

15. Chen WC, Magill ST, Wu A, Vasudevan HN, Morin O, Aghi MK, et al. Histopathological features predictive of local control of atypical meningioma after surgery and adjuvant radiotherapy. J Neurosurg. 2018;130(2):443-50.

16. Lee JJB, Lee J, Yoon HI, Kim SH, Cho J, Lee KS, et al. Analysis of patterns of failure and appraisal of postoperative radiation field for grade II-III meningioma. J Neurooncol. 2019;144(2):333-41.

17. Rogers L, Zhang P, Vogelbaum MA, Perry A, Ashby LS, Modi JM, et al. Intermediate-risk meningioma: initial outcomes from NRG oncology RTOG 0539. J Neurosurg. 2018;129(1):35-47.

18. Weber DC, Ares C, Villa S, Peerdeman SM, Renard L, Baumert BG, et al. Adjuvant postoperative high-dose radiotherapy for atypical and malignant meningioma: a phase-II parallel non-randomized and observation study (EORTC 22042-26042). Radiother Oncol. 2018;128(2):260-5.

19. NRG Oncology. Phase III Trial (NRG-BN003) of Observation Versus Irradiation for a Gross Totally Resected Grade II Meningioma. In: ClinicalTrials. gov [Internet]. https:/clinicaltrials.gov/ct2/show/NCT03180268. NLM Identifier: NCT03180268.

20. Jenkinson MD, Javadpour M, Haylock BJ, Young B, Gillard H, Vinten J, et al. The ROAM/EORTC-1308 trial: radiation versus observation following surgical resection of atypical meningioma: study protocol for a randomised controlled trial. Trials. 2015;14(16):519.

21. Liberati A, Altman DG, Tetzlaff J, Mulrow C, Gotzsche PC, loannidis JP, et al. The PRISMA statement for reporting systematic reviews and meta-analyses of studies that evaluate healthcare interventions: explanation and elaboration. BMJ. 2009;21(339):b2700.

22. Morrison A, Polisena J, Husereau D, Moulton K, Clark M, Fiander M, et al. The effect of English-language restriction on systematic review-based meta-analyses: a systematic review of empirical studies. Int J Technol Assess Health Care. 2012:28(2):138-44

23. Kim SY, Park JE, Lee YJ, Seo HJ, Sheen SS, Hahn S, et al. Testing a tool for assessing the risk of bias for nonrandomized studies showed moderate reliability and promising validity. J Clin Epidemiol. 2013;66(4):408-14.

24. Tierney JF, Stewart LA, Ghersi D, Burdett S, Sydes MR. Practical methods for incorporating summary time-to-event data into meta-analysis. Trials. 2007;7(8):16.

25. Balduzzi S, Rucker G, Schwarzer G. How to perform a meta-analysis with R: a practical tutorial. Evid Based Ment Health. 2019;22(4):153-60.

26. Wang YC, Chuang CC, Wei KC, Hsu YH, Hsu PW, Lee ST, et al. Skull base atypical meningioma: long term surgical outcome and prognostic factors. Clin Neurol Neurosurg. 2015;128:112-6.

27. Jiang Y, Lv L, Li J, Ma W, Chen C, Zhou P, et al. Clinical features, radiological findings, and treatment outcomes of high-grade lateral ventricular meningiomas: a report of 26 cases. Neurosurg Rev. 2020;43(2):565-73.

28. Condra KS, Buatti JM, Mendenhall WM, Friedman WA, Marcus RB Jr, Rhoton AL. Benign meningiomas: primary treatment selection affects survival. Int J Radiat Oncol Biol Phys. 1997;39(2):427-36.

29. Jo K, Park HJ, Nam DH, Lee Jl, Kong DS, Park K, et al. Treatment of atypical meningioma. J Clin Neurosci. 2010;17(11):1362-6.

30. Lee KD, DePowell JJ, Air EL, Dwivedi AK, Kendler A, McPherson CM. Atypical meningiomas: is postoperative radiotherapy indicated? Neurosurg Focus. 2013;35(6):E15.

31. Endo T, Narisawa A, Ali HS, Murakami K, Watanabe T, Watanabe M, et al. A study of prognostic factors in 45 cases of atypical meningioma. Acta Neurochir (Wien). 2016;158(9):1661-7.
32. Yip CM, Hsu SS, Liao WC, Chen JY, Liu SH, Chen CH, et al. Intracranial atypical meningiomas: a case series. J Med Sci. 2016;36(3):108-12.

33. Cho M, Joo JD, Kim IA, Han JH, Oh CW, Kim CY. The role of adjuvant treatment in patients with high-grade meningioma. J Korean Neurosurg Soc. 2017;60(5):527-33.

34. Dohm A, McTyre ER, Chan MD, Fan C, Isom S, Bourland JD, et al. Early or late radiotherapy following gross or subtotal resection for atypical meningiomas: clinical outcomes and local control. J Clin Neurosci. 2017;46:90-8.

35. Budohoski KP, Clerkin J, Millward CP, O'Halloran PJ, Wagar M, Looby S, et al. Predictors of early progression of surgically treated atypical meningiomas. Acta Neurochir (Wien). 2018;160(9):1813-22.

36. Shakir SI, Souhami L, Petrecca K, Mansure JJ, Singh K, Panet-Raymond V, et al. Prognostic factors for progression in atypical meningioma. J Neurosurg. 2018;129(5):1240-8.

37. Li H, Zhang YS, Zhang GB, Zhang GJ, Wang B, Li D, et al. Treatment protocol, long-term follow-up, and predictors of mortality in 302 cases of atypical meningioma. World Neurosurg. 2019;122:e1275-84.

38. Ros-Sanjuan A, Iglesias-Morono S, Carrasco-Brenes A, Bautista-Ojeda D, Arraez-Sanchez MA. Atypical meningiomas: histologic and clinical factors associated with recurrence. World Neurosurg. 2019;125:e248-56.

39. Wang F, Xu D, Liu Y, Lin Y, Wei Q, Gao Q, et al. Risk factors associated with postoperative recurrence in atypical intracranial meningioma: analysis of 263 cases at a single neurosurgical centre. Acta Neurochir (Wien) 2019;161(12):2563-70.

40. Zeng Q, Shi F, Guo Z. Effectiveness of postoperative radiotherapy on atypical meningioma patients: a population-based study. Front Oncol. 2019;9:34.

41. Zhi M, Girvigian MR, Miller MJ, Chen JC, Schumacher AJ, Rahimian J, et al. Long-term outcomes of newly diagnosed resected atypical meningiomas and the role of adjuvant radiotherapy. World Neurosurg. 2019;122:e1153-61.

42. Lee G, Lamba N, Niemierko A, Kim DW, Chapman PH, Loeffler JS, et al. Adjuvant radiation therapy versus surveillance after surgical resection of atypical meningiomas. Int J Radiat Oncol Biol Phys. 2021;109(1):252-66.

43. Yu SQ, Wang JS, Ji N, Liu W, Qian K. Clinical characteristics and therapeutic strategies of atypical meningioma. Chin Med J (Engl). 2011;124(7):1094-6.

44. Aghi MK, Carter BS, Cosgrove GR, Ojemann RG, Amin-Hanjani S, Martuza $\mathrm{RL}$, et al. Long-term recurrence rates of atypical meningiomas after gross total resection with or without postoperative adjuvant radiation. Neurosurgery. 2009;64(1):56-60 (discussion 60).

45. Sun SQ, Kim AH, Cai C, Murphy RK, DeWees T, Sylvester P, et al. Management of atypical cranial meningiomas, part 1: predictors of recurrence and the role of adjuvant radiation after gross total resection. Neurosurgery. 2014;75(4):347-54 (discussion 54-5; quiz 55).

46. Kim SK, Yoon HI, Yoon WS, Cho JM, Moon J, Kim KH, et al. A national consensus survey for current practice in brain tumor management II: diffuse midline glioma and meningioma. Brain Tumor Res Treat. 2020;8(1):11-9.

47. Hasan S, Young M, Albert T, Shah AH, Okoye C, Bregy A, et al. The role of adjuvant radiotherapy after gross total resection of atypical meningiomas. World Neurosurg. 2015;83(5):808-15.

48. Perry A, Stafford SL, Scheithauer BW, Suman VJ, Lohse CM. Meningioma grading: an analysis of histologic parameters. Am J Surg Pathol. 1997:21(12):1455-65.

49. Nowak A, Dziedzic T, Krych P, Czernicki T, Kunert P, Marchel A. Benign versus atypical meningiomas: risk factors predicting recurrence. Neurol Neurochir Pol. 2015;49(1):1-10.

50. Kim D, Niemierko A, Hwang WL, Stemmer-Rachamimov AO, Curry WT, Barker FG, et al. Histopathological prognostic factors of recurrence following definitive therapy for atypical and malignant meningiomas. J Neurosurg. 2018;128(4):1123-32.

51. Chen WC, Hara J, Magill ST, Wu A, Aghi MK, Theodosopoulos PV, et al. Salvage therapy outcomes for atypical meningioma. J Neurooncol. 2018;138(2):425-33

52. Coggins WS, Pham NK, Nguyen AV, Branch DW, Guillet JY, Korst G, et al. A systematic review of ion radiotherapy in maintaining local control regarding atypical and anaplastic meningiomas. World Neurosurg. 2019;132:282-91.

53. Koch MJ, Agarwalla PK, Royce TJ, Shih HA, Oh K, Niemierko A, et al. Brachytherapy as an adjuvant for recurrent atypical and malignant meningiomas. Neurosurgery. 2019;85(5):E910-6. 
54. DziukTW, Woo S, Butler EB, Thornby J, Grossman R, Dennis WS, et al. Malignant meningioma: an indication for initial aggressive surgery and adjuvant radiotherapy. J Neurooncol. 1998;37(2):177-88.

55. Engenhart-Cabillic R, Farhoud A, Sure U, Heinze S, Henzel M, Mennel $\mathrm{HD}$, et al. Clinicopathologic features of aggressive meningioma emphasizing the role of radiotherapy in treatment. Strahlenther Onkol. 2006;182(11):641-6

56. Girvigian MR, Chen JC, Rahimian J, Miller MJ, Tome M. Comparison of early complications for patients with convexity and parasagittal meningiomas treated with either stereotactic radiosurgery or fractionated stereotactic radiotherapy. Neurosurgery. 2008;62(5 Suppl):A19-27 (discussion A27-8).
57. Fokas E, Henzel M, Surber G, Hamm K, Engenhart-Cabillic R. Stereotactic radiation therapy for benign meningioma: long-term outcome in 318 patients. Int J Radiat Oncol Biol Phys. 2014;89(3):569-75.

58. Kaur G, Sayegh ET, Larson A, Bloch O, Madden M, Sun MZ, et al. Adjuvant radiotherapy for atypical and malignant meningiomas: a systematic review. Neuro Oncol. 2014;16(5):628-36.

\section{Publisher's Note}

Springer Nature remains neutral with regard to jurisdictional claims in published maps and institutional affiliations.
Ready to submit your research? Choose BMC and benefit from:

- fast, convenient online submission

- thorough peer review by experienced researchers in your field

- rapid publication on acceptance

- support for research data, including large and complex data types

- gold Open Access which fosters wider collaboration and increased citations

- maximum visibility for your research: over 100M website views per year

At BMC, research is always in progress.

Learn more biomedcentral.com/submissions 